\title{
Abdominal stab wound with damage to the abdominal aorta and the left lobe of the liver - case report
}

\author{
JAN GNUS ${ }^{1,2}$, MICHAŁ KASPERCZAK ${ }^{2}$, STANISŁAW FERENC \\ ${ }^{1}$ Department of General and Vascular Surgery, Voivodeship Specialist Hospital, Research and Development Centre in Wroclaw \\ ${ }^{2}$ Departament of Physiotherapy Medical University of Wroclaw
}

Corresponding author

Michat Kasperczak

Departament of Physiotherapy, Medical University of Wroclaw Grunwaldzka 2, 50-355 Wroclaw, Poland

E-mail:mkasperczakmd@gmail.com

\section{ABSTRACT}

A case of a 26-year-old man with an abdominal stab wound damaging the abdominal aorta and the left lobe of the liver is presented here. The patient was diagnosed and operated on after an emergency admission. The patient was discharged from the Surgical Ward 10 days after surgery in good general condition and was referred to the out-patient clinic.

Key words: abdominal stab wounds, liver, abdominal aorta

\section{INTRODUCTION}

Two types of abdominal injuries can be distinguished: blunt and penetrating trauma. The largest number of stab and gunshot wounds to the abdomen are found in the USA, South Africa and South America. Until the end of the 20th century, most hospital admissions for abdominal trauma in Great Britain, Australia, New Zealand and the European Union, were related to blunt injuries. However, in the last decade a significant increase in abdominal stab wounds has been observed in the aforementioned countries.

The highest mortality rate among patients who survive extensive injury to the abdomen and are transported to hospital is found in two treatment stages. The first mortality peak, occurring in the Emergency Room (ER) and Operating Room, is caused by significant damage to the vascular system or due to multiorgan trauma of the abdomen. (1) The second peak consists of patients who survive the first phase of resuscitation and are susceptible to a number of life-threatening complications, such as SIRS. (1) Complications related to blood loss and massive transfusion are one of the most significant causes of death. This is a significant factor for tissue function disorders in the course of post-traumatic stress.

\section{CASE REPORT}

A 26-year-old patient was admitted as a medical emergency to the Department of General Surgery on account of his abdominal stab wound. On admission, the patient was unconscious with a blood pressure of 90/60 $\mathrm{mmHg}$, heartbeat of 120 beats per minute (BPM) and saturation of $55.1 \%$. Complete blood count was ordered along with arterial blood gases, sodium, potassium, creatinine, coagulation factors, and a computed tomography (CT) scan.

A lower haematocrit, i.e. $27 \%(40-51 \%)$ and haemoglobin $8.5 \mathrm{~g} / \mathrm{dL}(14-18 \mathrm{~g} / \mathrm{dL})$, along with a lower red blood cell count of $2.72 \mathrm{M} / \mu \mathrm{L}(4.2-5.4 \mathrm{M} / \mu \mathrm{L})$, were found. Arterial blood gases revealed significant acidosis with a $\mathrm{pH}$ of 7.108 (7.35 - 7.45), together with $\mathrm{PaO} 2$ of $42 \mathrm{mmHg}(75-100$ $\mathrm{mmHg})$ and $\mathrm{PaCO} 2$ of $51 \mathrm{mmHg}(32-45$ $\mathrm{mmHg}), \mathrm{HCO} 3-$ of $15.3 \mathrm{mmol} / \mathrm{L}(21-27$ $\mathrm{mmol} / \mathrm{L}$ ) and $\mathrm{ctCO} 2$ of $15.7 \mathrm{mmol} / \mathrm{L}(22$ $-28 \mathrm{mmol} / \mathrm{L})$. The concentration of lactic acid in the blood amounted to $6.2 \mathrm{mmol} / \mathrm{L}$ (0.5-1.5 mmol/L), with $\mathrm{BE}$ of $13.2 \mathrm{mEq} / \mathrm{L}$ $(-2.3-2.3 \mathrm{mEq} / \mathrm{L})$.

Multiphase and normal contrast-enhanced CT was performed. The scan revealed damage to the anterior wall of the abdominal aorta, around $3.2 \mathrm{~cm}$ above the origin of the celiac trunk. The wound canal was located in the lobe of the liver. Inside the lobe, a haematoma was discovered together with extensive parenchymal injury (Figure 1). The patient qualified for emergency surgery.

The operation was performed in the first hour after admission. The abdominal cavity was opened with a lengthwise incision widening the entry point of the stab wound.

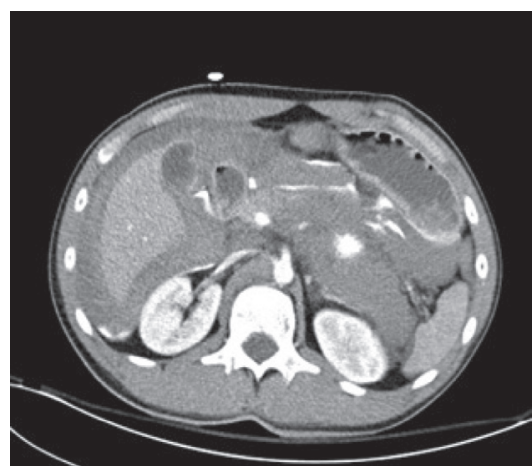

Figure 1. Selected image from computed tomography of abdomen

The peritoneal cavity was filled with fresh blood. The blood was drained and the abdominal organs were examined. The stab wound, piercing the left lobe of the liver, was revealed, along with a massive retroperitoneal haematoma. After evacuation of the haematoma, a 3-cm linear lesion was found in the anterior wall of the abdominal aorta, above the celiac trunk, with massive bleeding. The point of bleeding from the aorta was pressed and stitched with continuous vascular stitches, which stopped the bleeding. The liver was stitched using a flat, hepatic, absorbable suture (Parenchyma). Due to massive blood loss at the end of the operation, bleeding from the tissue surface, characteristic of coagulation factor deficiency, was seen in spite of blood plasma transfusion. Two drains were fixed, the right one below the liver and the left one in the recto-uterine pouch. The abdominal wall was stitched with two-layer stitches. Due to the seriousness of the condition, the patient was transferred to the Intensive Care Unit for further observation. Augmentin and Metronidazole were administered intravenously for prophylaxis. Dur- 
ing the course of hospitalization, 18 units of packed blood cells and 12 units of blood plasma were transfused. The patient's condition stabilized as a result of treatment in the Intensive Care Unit. After 10 days, the patient was discharged from the Department of General Surgery and referred for ambulatory treatment.

\section{DISCUSSION}

Around $5 \%$ of cases of abdominal stab and blunt trauma include injuries to the liver (2). This is related to perioperative mortality, rate ranging from $67 \%$ to $80 \%$ in grade $\mathrm{V}$ liver trauma injuries. (3) The liver injury in our described case was classified as grade III, according to the liver trauma injury grading, which significantly increased the patient's survival chance. Damage to the aorta due to a stab wound or blunt abdominal trauma, is responsible for only $5 \%$ of all aorta injuries, (4-6) which is related to the retroperitoneal location of the aorta. In $98 \%$ of cases, the injury involves the sub-renal part of the aorta. (4) Therefore, the described case of injury to the adrenal abdominal aorta is a rare finding in abdominal trauma surgery.

There are many surgical methods to stop bleeding from the liver. If damage involves only the hepatic parenchyma, coagulation, ligation of smaller vessels and perihepatic packing are the only methods to prevent bleeding in the long run. When larger vessels such as the portal vein, common hepatic artery or proper hepatic artery are damaged, application of endovascular techniques should be considered (e.g. stent implantation). The injury of the abdominal aorta can be managed with an open operation or endovascular technique using a stent graft. The treatment choice depends on the patient's general condition and available facilities.

In this case, the decision to perform open surgery was based on CT scans and the risk of damage to other abdominal tissues, invisible on imaging. Based on the CT scan, it was not possible to evaluate damage to the hepatic parenchyma of the left lobe and its vessels, which resulted in massive bleeding from the abdominal aorta and blood vessels of the liver. Endovascular treatment of the abdominal aorta was also relatively unsafe due to the location of the lesion below the celiac trunk.

\section{CONCLUSION}

Every case of abdominal stab wound injury, admitted to hospital as an emergency, should be evaluated individually by doctors specialized in various fields. Guidelines regarding diagnostics and radical surgery depend on the wound size, location, and depth of the wound, along with the patient's general condition.

\section{REFERENCES}

1. Brooks A, Simpson JAD. Blunt and penetrating abdominal trauma. Surgery 2009;27(6):266-71.

2. Fabian TC, Bee TK. Liver and biliary tract. In: Mattox KL, Moore EK, Feliciano DV, editors. Trauma, 7th ed. The McGraw-Hill Companies, Inc. 2012.p.539-60.

3. Chen RJ, Fang JF, Lin BC, Hsu YP, Kao JL, Chen MF. Factors determining operative mortality of grade V blunt hepatic trauma. J Trauma 2000;49(5):886-91.

4. Steenburg SD, Ravenel JG. Multidetector computed tomography findings of atypical blunt traumatic aortic injuries: a pictorial review. Emerg Radiol 2007;14(3):143-50.

5. Daly KP, Ho CP, Persson DL, Gay SB. Traumatic retroperitoneal injuries: review of multidetector CT findings. Radiographics 2008;28:1571-90.

6. Michaels AJ, Gerndt SJ, Taheri PA. Blunt force injury of the abdominal aorta. J Trauma 1996;41(1):105-9. 